\title{
Tandem Mass Tag Based Quantitative Proteomics of Developing Sea Buckthorn Berries Reveals Candidate Proteins Related to Lipid Metabolism
}

Wei Dü, Chao-Wei Xiong ${ }^{\dagger}$, Jian Ding ${ }^{\dagger}$, Hilde Nybom ${ }^{\dagger}$, Cheng-Jiang Ruan ${ }^{\dagger, *}$ Hai Guo ${ }^{\S, \perp}$

${ }^{\dagger}$ Institute of Plant Resources, Key Laboratory of Biotechnology and Bioresources Utilization, Ministry of Education, Dalian Nationalities University, Dalian 116600, China;

*Department of Plant Breeding, Swedish University of Agricultural Sciences, Fjälkestadsvägen 459, SE-291 94 Kristianstad, Sweden.

${ }^{\S}$ Conseco Seabuckthorn Co. Ltd, Beijing 100038, China

${ }^{\perp}$ InnerMongolia Hijing Environment Protection Science and Technology Co. Ltd, Erdos InnerMongolia 017000, China

*Correspondence to Cheng-Jiang Ruan, Institute of Plant Resources, Key Laboratory of Biotechnology and Bioresources Utilization, Ministry of Education, Dalian Nationalities University, Dalian 116600, China; Ph.: +86 0411 87652536; Email: ruan@dlnu.edu.cn 


\section{Supplementary Information}

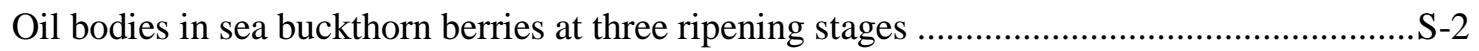

Figure S1 Oil bodies in sea buckthorn berries at three ripening stages...................................

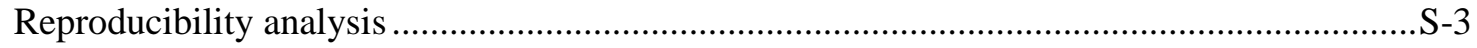

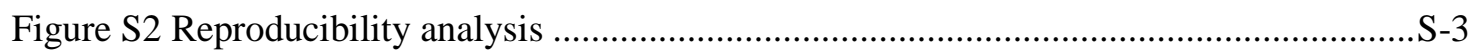

Figure S3.Cluster analysis of three technical replication....................................

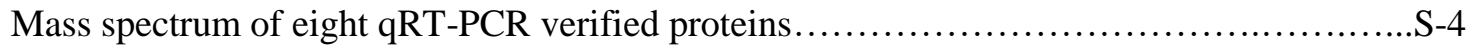

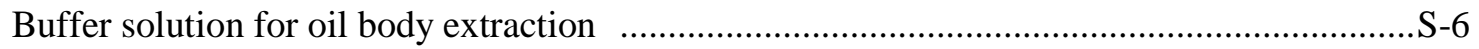

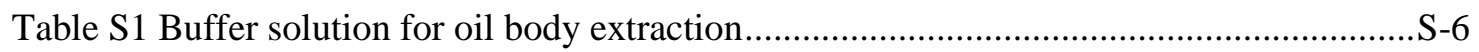

Protein MS identified information. xlsx

Table S2 Protein MS identified information.......................................

\section{Oil bodies in sea buckthorn berries at three ripening stages}

A

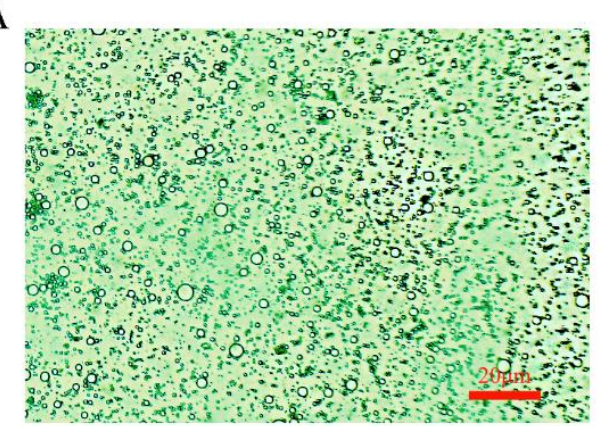

B

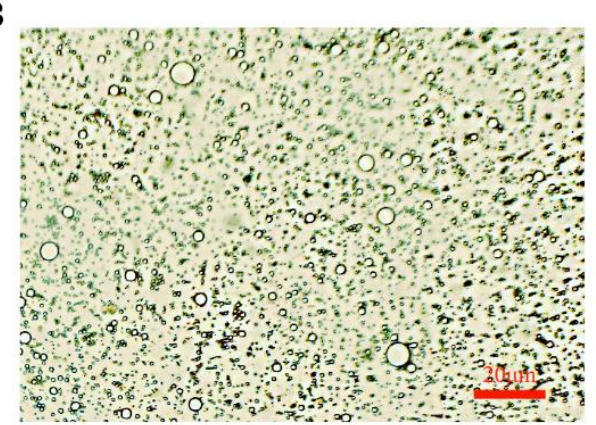

$\mathrm{C}$

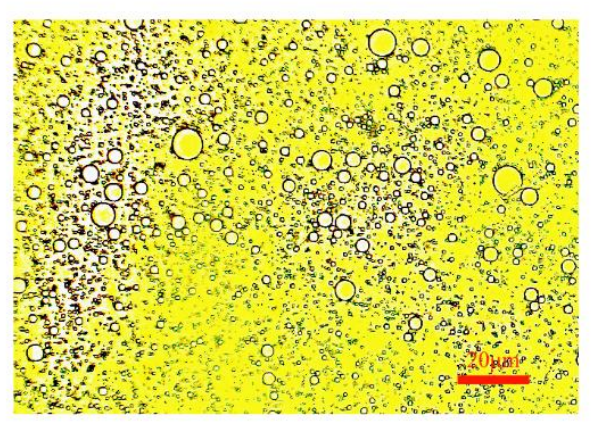

Figure S1. Oil bodies in sea buckthorn berries at three ripening stages. Bar: $20 \mu \mathrm{m}$. (A) $30 \mathrm{DAF}$, (B) $50 \mathrm{DAF}$, (C) $70 \mathrm{DAF}$ 


\section{Reproducibility analysis}

\begin{tabular}{|c|c|c|c|c|c|c|c|c|}
\hline \multirow{2}{*}{\multicolumn{2}{|c|}{ Pearson Correlation }} & \multicolumn{2}{|c|}{$\mathrm{N}-1 / \mathrm{N}-2$} & \multicolumn{2}{|c|}{$N-2 / N-3$} & \multicolumn{2}{|c|}{$\mathrm{N}-1 / \mathrm{N}-3$} & \multirow{2}{*}{$\begin{array}{llllll}\text { Pearson Correlation } & \\
& & & & \\
-1 & -0.5 & 0 & 0.5 & 1\end{array}$} \\
\hline & & repeat1 & repeat2 & repeat1 & repeat2 & repeat1 & repeat2 & \\
\hline \multirow{2}{*}{$\mathrm{N}-1 / \mathrm{N}-2$} & repeat1 & 1.00 & 0.87 & 0.11 & 0.17 & 0.79 & 0.74 & \\
\hline & repeat2 & 0.87 & 1.00 & 0.19 & 0.08 & 0.72 & 0.79 & \\
\hline \multirow{2}{*}{$\mathrm{N}-2 / \mathrm{N}-3$} & repeat1 & 0.11 & 0.19 & 1.00 & 0.82 & 0.70 & 0.63 & \\
\hline & repeat2 & 0.17 & 0.08 & 0.82 & 1.00 & 0.62 & 0.68 & \\
\hline \multirow{2}{*}{$\mathrm{N}-\mathbf{1} / \mathrm{N}-3$} & repeat1 & 0.79 & 0.72 & 0.70 & 0.62 & 1.00 & 0.90 & \\
\hline & repeat2 & 0.74 & 0.79 & 0.63 & 0.68 & 0.90 & 1.00 & \\
\hline
\end{tabular}

Figure S2. Analysis of reproducibility for two repeated experiments by Pearson correlation coefficient. (N-1:30 DAF, N-2:50 DAF, N-3:70 DAF)

We introduce the Pearson correlation coefficient to examine the correlation of two biological replications (Figure S2). Pearson correlation coefficient close to -1 means the two replications were negatively correlated, 0 means no correlation and 1 means positive correlation. The two biological replications can meet the standard of consistency for biological repetition quantification if Pearson correlation coefficient was greater than 0.6. The positive correlation between repeated experiments were shown in Figure S2, there was a significant positive correlation between the same treatment groups.

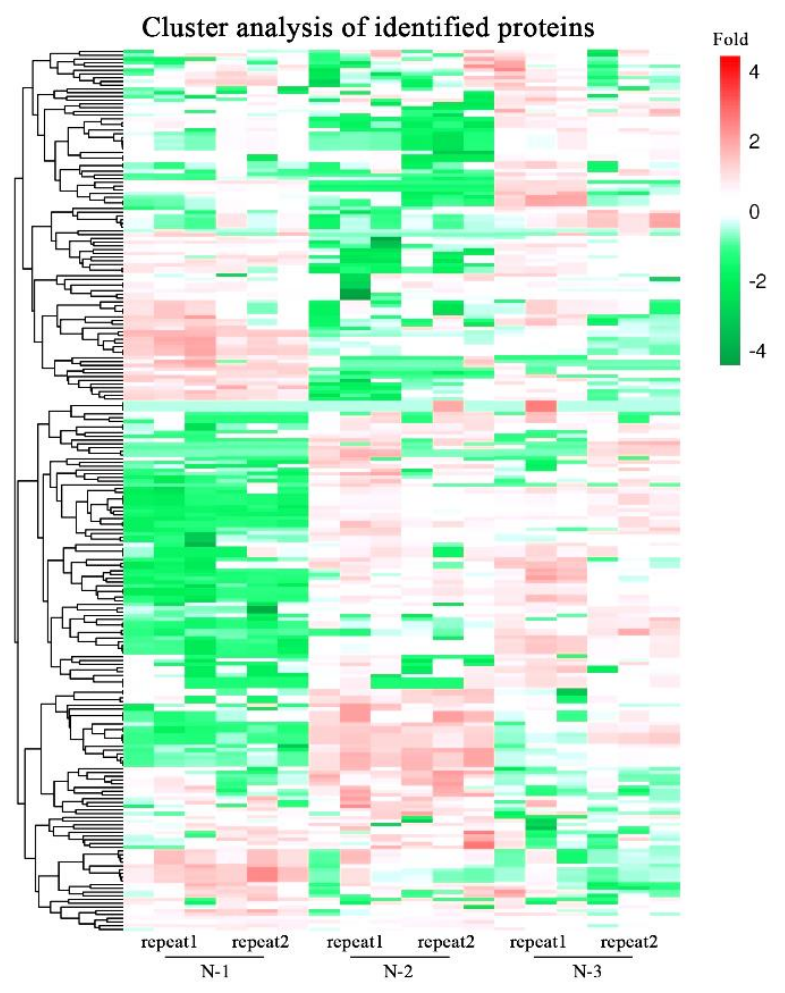

Figure S3. Cluster analysis of three technical replication. (N-1:30 DAF, N-2:50 DAF, N-3:70 DAF) 
Mass spectrum of eight $q R T-P C R$ verified proteins.

ACCuse:

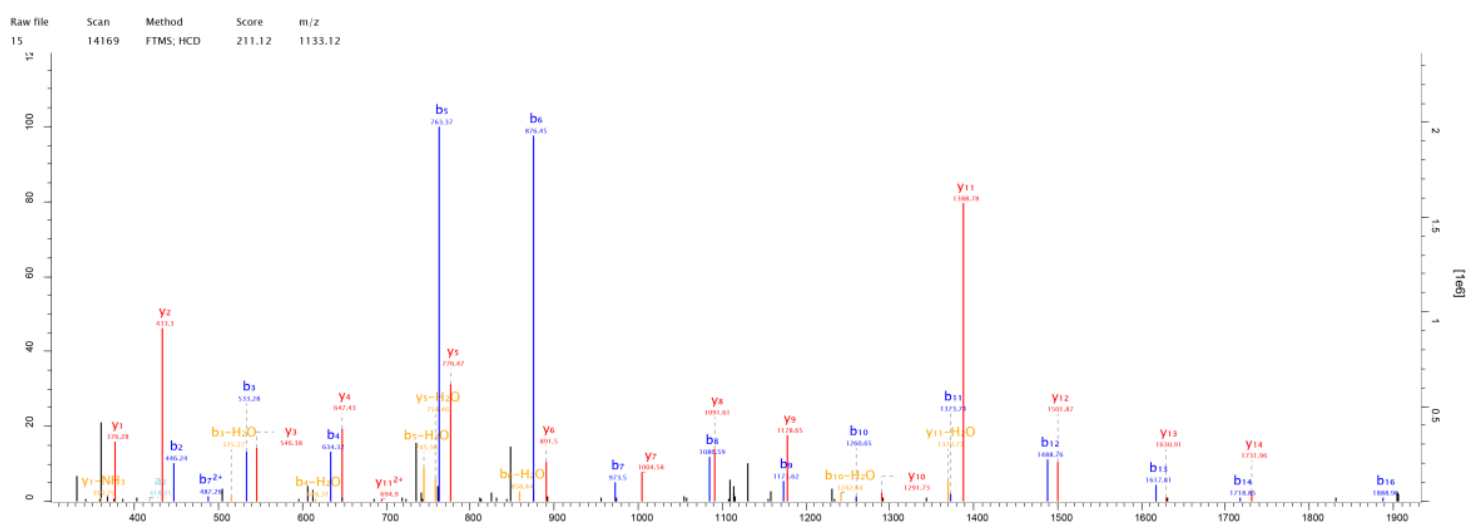

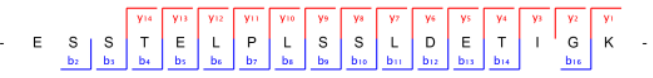

DGAT1:

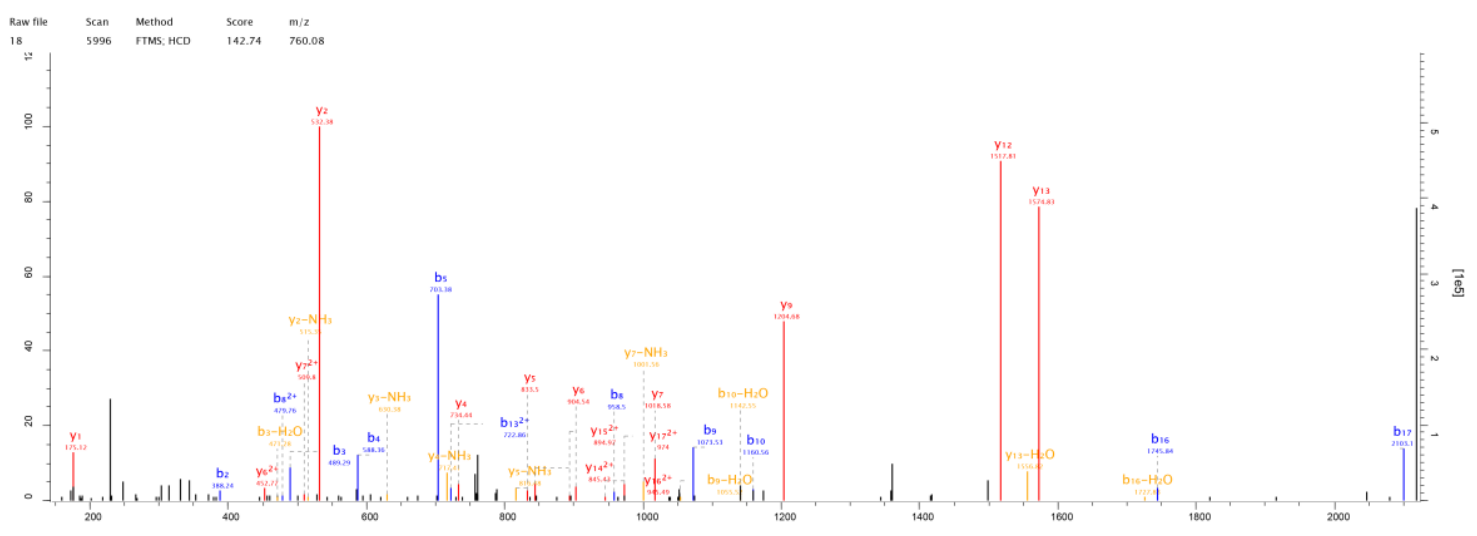

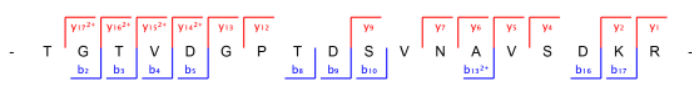

FAD:

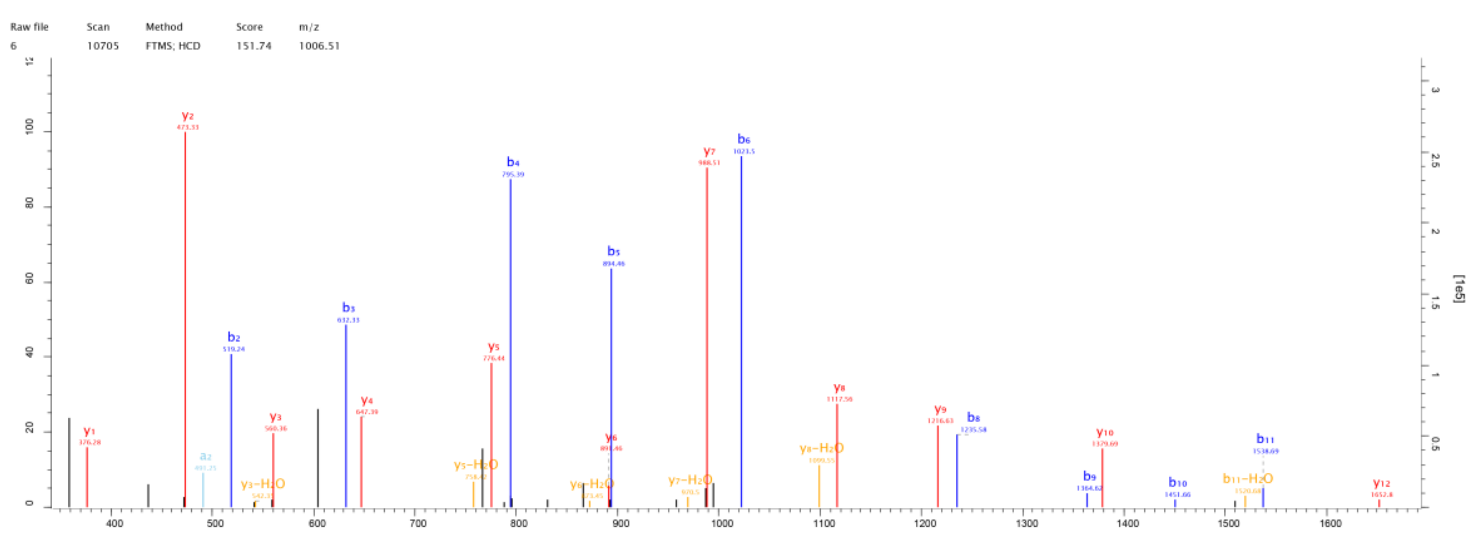

- E E E E

S-4 
FAD3:

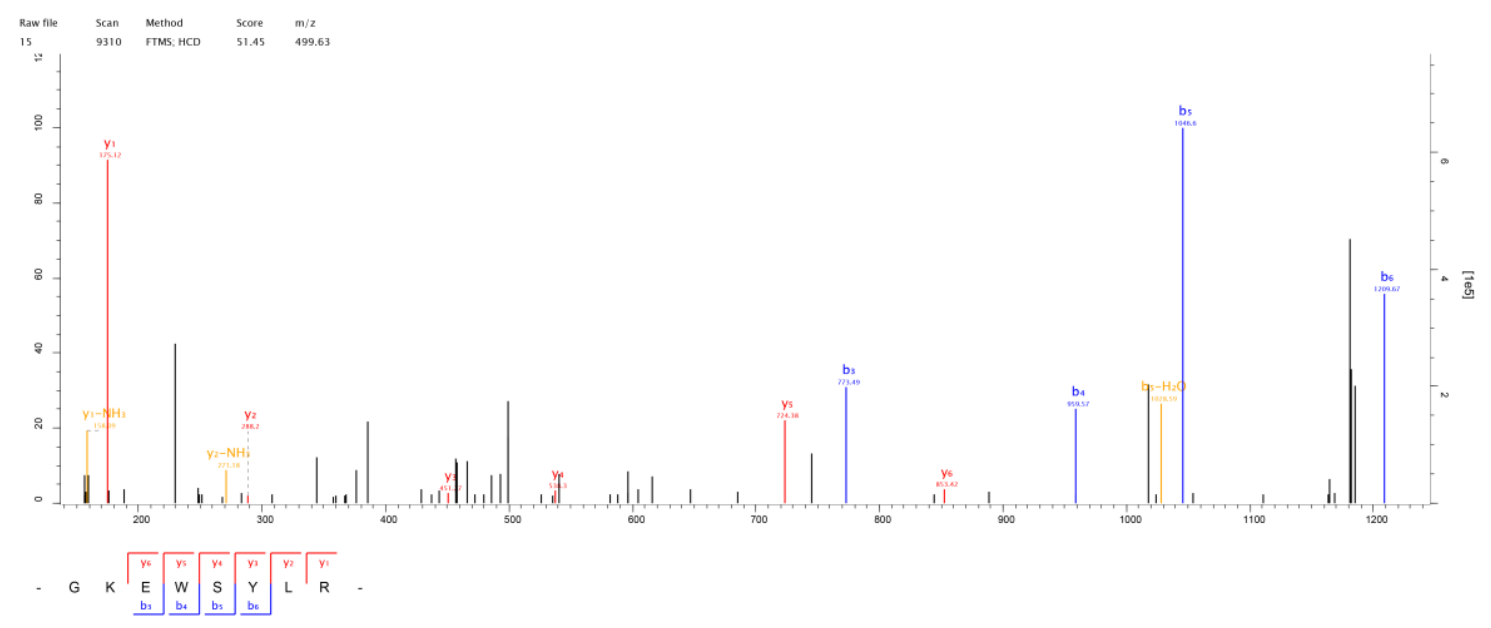

GPAT:

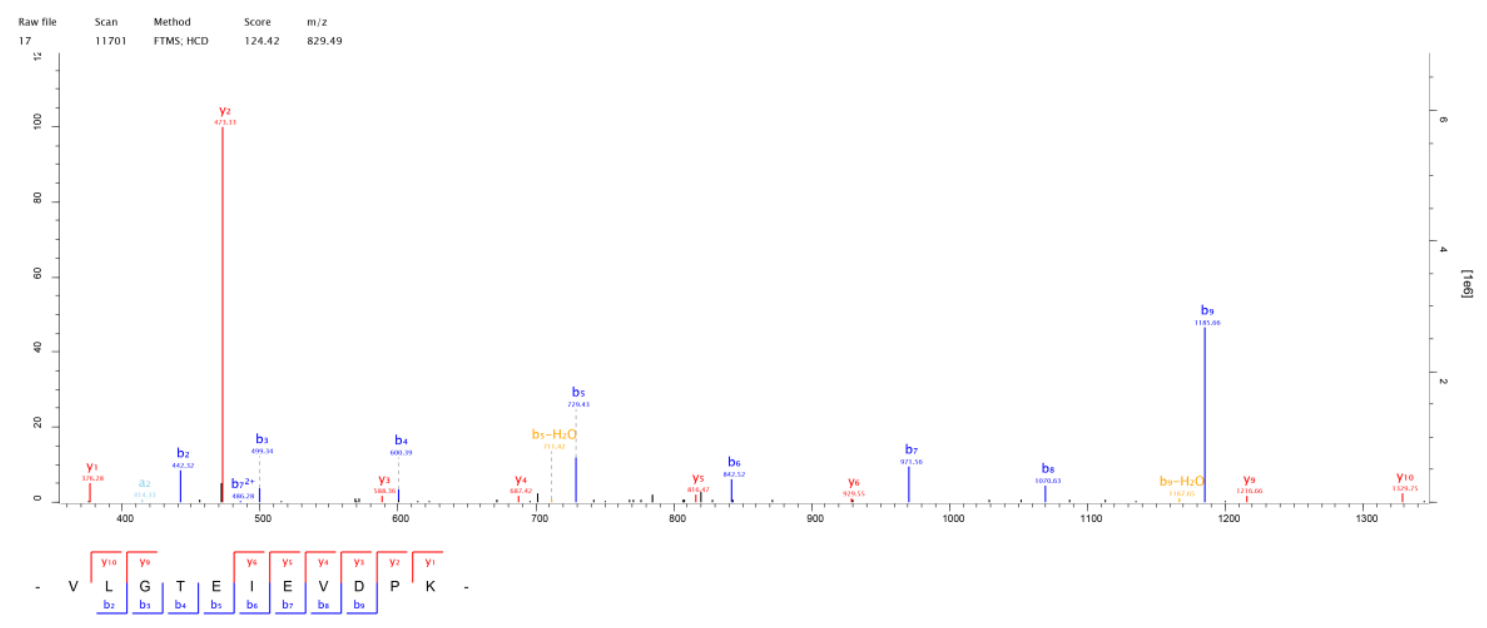

KASIII:

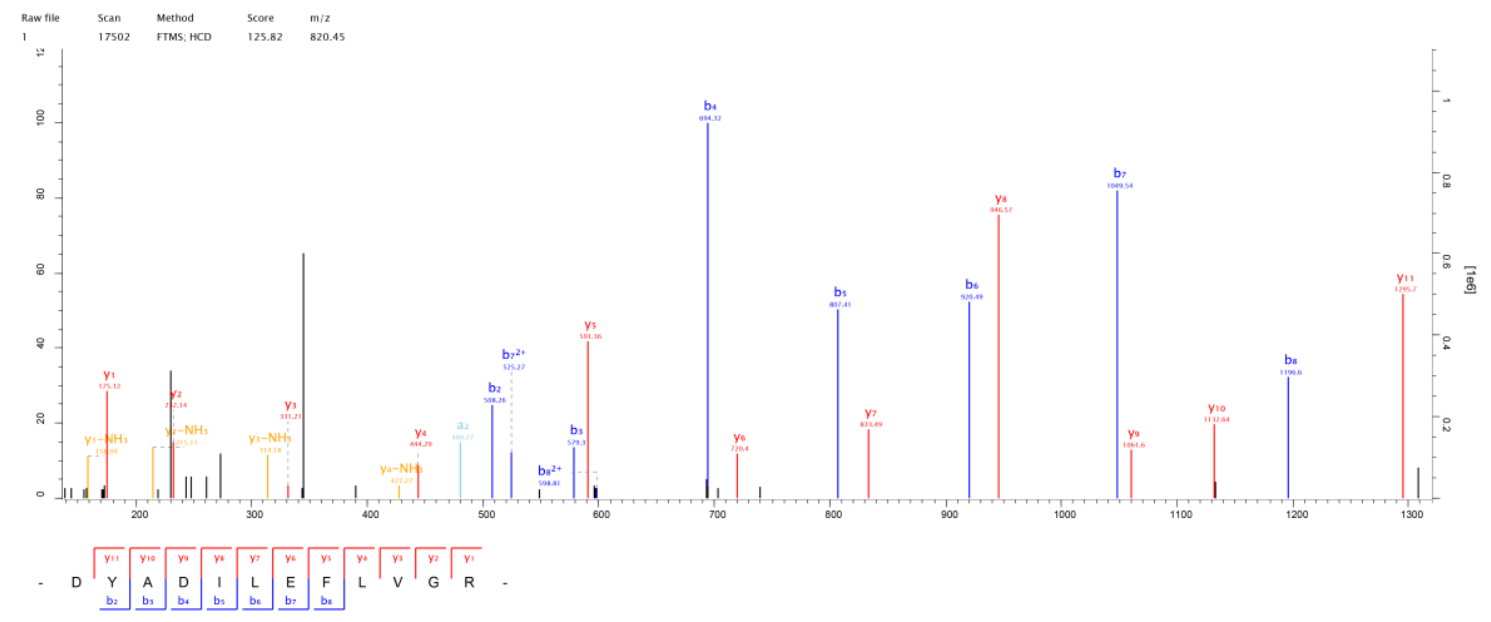


LPCAT:

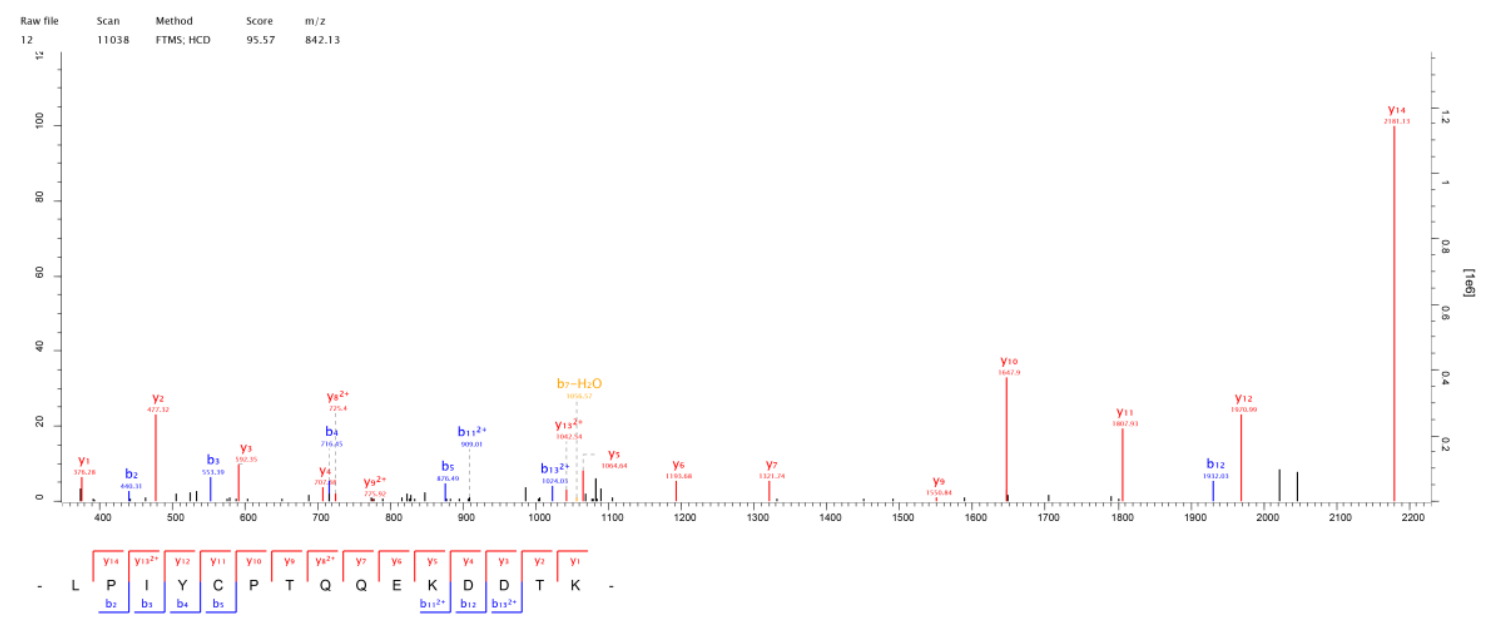

PDAT:

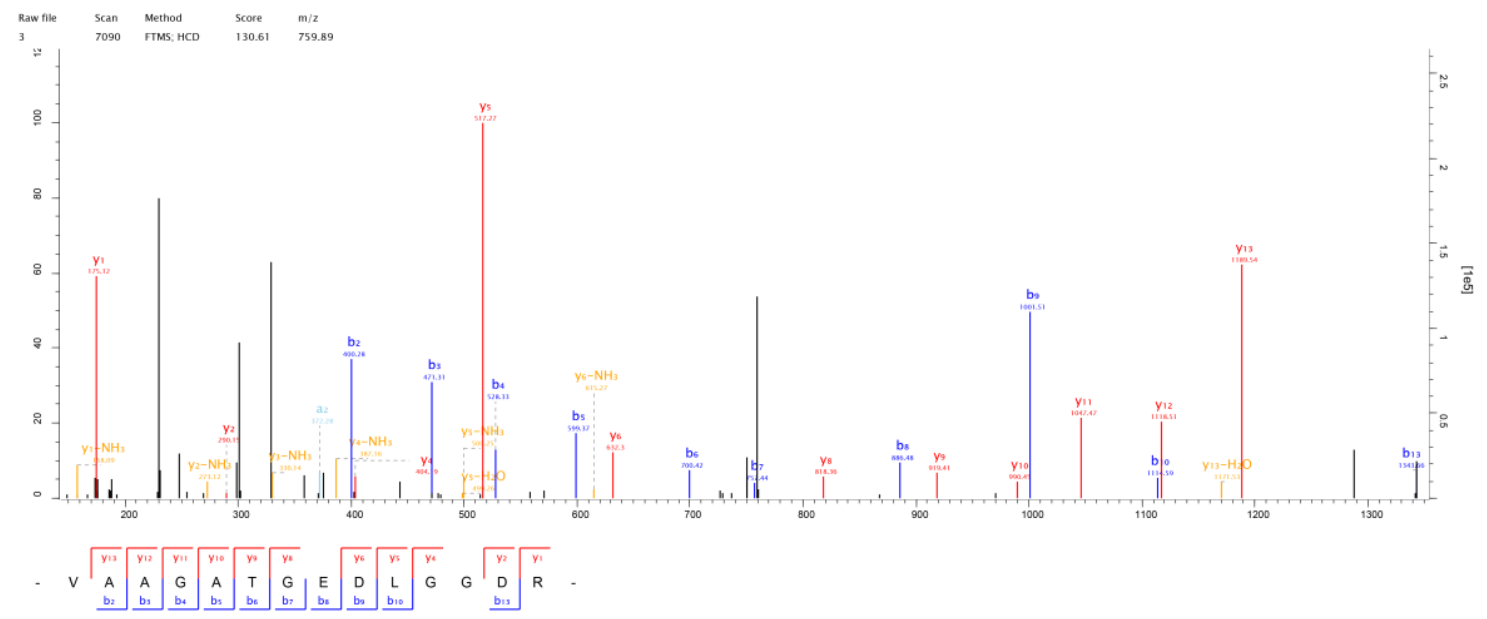

Table S1 Buffer solution for oil body extraction

Table S1. Buffer solution for oil body extraction.

\begin{tabular}{lccccccc}
\hline & $\begin{array}{c}\text { EDTA } \\
(\mathrm{mM})\end{array}$ & $\begin{array}{c}\mathrm{KCl} \\
(\mathrm{mM})\end{array}$ & $\begin{array}{c}\mathrm{MgCl}_{2} \\
(\mathrm{mM})\end{array}$ & $\begin{array}{c}\mathrm{DTT} \\
(\mathrm{mM})\end{array}$ & $\begin{array}{c}\text { Sucrose } \\
(\mathrm{M})\end{array}$ & $\begin{array}{c}\text { Tricine-KOH } \\
\mathrm{pH} 7.5(\mathrm{M})\end{array}$ & $\begin{array}{c}\mathrm{NaCl} \\
(\mathrm{M})\end{array}$ \\
\hline Buffer solution A & 1 & 8 & 1 & 2 & 0.6 & 0.15 & 0 \\
Buffer solution B & 1 & 8 & 1 & 2 & 1 & 0.15 & 0 \\
Buffer solution C & 1 & 8 & 1 & 2 & 0.6 & 0.15 & 2 \\
Buffer solution D & 1 & 8 & 1 & 2 & 1 & 0.15 & 2 \\
\hline
\end{tabular}

